\title{
Maternal pre-pregnancy underweight as a risk factor for mother and child: analysis of the birth cohort Survey of Neonates in Pomerania I
}

\author{
Grzegorz Domanski \\ dept. of Neonatology and Pediatric Intensive Care, University Medicine Greifswald \\ Anja Erika Lange \\ Dept. of Neonatology and Pediatric Intensive Care, University Medicine Greifswald \\ Till Ittermann \\ Institute for Community Medicine, University of Greifswald \\ Jonas Fallenberg \\ Dept. of Neonatology and Pediatric Intensive Care, University Medicine Greifswald \\ Heike Allenberg \\ Dept. of Neonatology and Pediatric Intensive Care, University Medicine Greifswald \\ Marek Tadeusz Zygmunt \\ Dep. of Gynecology and Obstetrics, University Medicine Greifswald \\ Matthias Heckmann ( $\square$ matthias.heckmann@uni-greifswald.de) \\ Universitatsmedizin Greifswald https://orcid.org/0000-0002-5260-264X
}

Research article

Keywords: birth cohort study, pre-pregnancy BMI, underweight, neonatal outcome, SNiP

Posted Date: April 20th, 2020

DOI: https://doi.org/10.21203/rs.3.rs-23082/v1

License: (c) (i) This work is licensed under a Creative Commons Attribution 4.0 International License. Read Full License 


\section{Abstract}

Background: The prevalence of pre-pregnancy underweight (BMI (body mass index) $<18.5 \mathrm{~kg} / \mathrm{m}^{2}$ ) varies between $3 \%$ in Europe and $17 \%$ in Asia. IIlness and low socioeconomic status may be associated with pre-pregnancy underweight which then may result in adverse pregnancy and neonatal outcome.

Methods: We analysed pre-pregnancy BMI categories using data from the population-based birth cohort Survey of Neonates in Pomerania 2002-2008 (SNiP) in north-eastern Germany. Multivariable regression analyses adjusted for confounding were used to investigate a) socio-economic risk factors for underweight before pregnancy and b) associations of underweight with pregnancy and neonatal outcomes.

Results: Chronic pre-pregnancy diseases were not more frequent in underweight pregnant women. Bivariate analyses showed that underweight women were younger by three years $(p<0.001)$, smoked twice as often $(p<0.001)$, and less likely graduated from high school $(p<0.001)$ compared to women with normal weight. The former were more often unemployed $(p<0.001)$ and had lower available net-income $(p<0.001)$. However, multivariable regression analysis adjusted for confounders revealed that only a younger age (0.90 (0.88-0.92) and smoking (RR 2.52 (1.89-3.41) remained associated with underweight. Compared to women with normal pre-pregnancy BMI, underweight women had an increased risk of premature labour $(\mathrm{OR}=1.74 ; 95 \% \mathrm{Cl}$ : $1.29-2.36)$ and a reduced placental weight. No association was found between pregnancy-induced hypertension, gestational diabetes, preeclampsia, mode of birth and pre-pregnancy underweight. The offspring of underweight women had an increased risk of late preterm birth $(\mathrm{OR}=1.79 ; 95 \% \mathrm{Cl}$ : 1.17-2.73) or birth with birth weight <2500g $(\mathrm{OR}=1.99 ; 95 \% \mathrm{Cl}: 1.24-3.21)$.

Conclusions: Smoking during pregnancy and a younger age were identified as risk factors for maternal pre-pregnancy underweight which then was associated with preterm birth and low birth weight. Targeted measures like smoking cessation programs and counselling young women about the risk of staying too slim particularly for the offspring may improve outcome.

\section{Background}

Maternal obesity, defined as body mass index $(\mathrm{BMI}) \geq 30 \mathrm{~kg} / \mathrm{m}^{2}$, is widely recognised as an important risk factor for pregnant women and their offspring [1, 2]. In contrast, the influence of maternal underweight, defined as $\mathrm{BMI}<18.5 \mathrm{~kg} / \mathrm{m}^{2}$ on perinatal and neonatal outcomes has been less intensively studied although it may adversely influence perinatal outcomes and health status in later life. Furthermore, the prevalence of pre-pregnancy underweight is 3,5 and $17 \%$ in Europe, USA and Asia, respectively [3]. Infants of underweight women are more exposed to higher risk of preterm birth, and to be small for gestational age (SGA) [4-6]. Preterm birth may affect short- und long-term outcome even in late preterm infants [7, 8]. In addition, SGA and low birth weight are associated with cardiovascular disease in later life [9]. Tobacco smoking is listed as a one of the major risk factors for low birth weight and fetal growth restriction [10]. Low socioeconomic status, chronic diseases and behaviour with respect to body image may contribute to underweight in women high-income countries [11-13]. However, the combined effect of maternal pre-pregnancy underweight, tobacco smoking and adverse socioeconomic status on pregnancy and neonatal outcomes remains unclear.

Thus, our aim was to investigate 1) how socioeconomic status (educational level, income, employment status), and adverse habits (smoking and alcohol consumption) were associated with pre-pregnancy $\mathrm{BMI}<18.5 \mathrm{~kg} / \mathrm{m}^{2}$; and 2) how maternal pre-pregnancy BMI $<18.5 \mathrm{~kg} / \mathrm{m}^{2}$ was associated with pregnancy and neonatal outcomes. Our hypothesis was that, in a rural birth cohort, low socioeconomic status is associated with low pre-pregnancy BMI resulting in adverse pregnancy and neonatal outcomes compared to women with normal weight.

\section{Material And Methods}

\section{Design of the SNiP-I study}

The present study is part of the population-based birth cohort study 'Survey of Neonates in Pomerania' (SNiP-I). The design of the SNiP-I study has been described in detail by Ebner et al [14]. In short, the SNiP-I study was conducted from February 2002 to November 2008 in the region of Pomerania in Northeastern Germany. More than 270 variables covering personal data, medical records and socioeconomic background were collected and recorded from each participating mother-child dyad. From all non-participants, excluded individuals and non-responders, a minimum dataset was compiled comprising data on the health status of women and their newborns but lacking detailed information about environmental parameters.

\section{Population}

The baseline of the SNiP-I birth cohort includes data on 5,800 mother-child-dyads. For the purpose of this analysis, only singleton pregnancies with life or stillbirth and with known maternal pre pregnancy BMI were included. This subpopulation of the baseline SNiP-I birth cohort comprised 4,667 mother-childdyads (Figure 1).

\section{Pre-pregnancy Body-Mass-Index (BMI)}

Women were categorised into different BMI groups according to the classification recommended by WHO [15]. Height (in cm) and pre-pregnancy body mass (in $\mathrm{kg}$ ) were reported by women using a standardised self-administrated questionnaire during the stay at the obstetrical ward. The content of this questionnaire was described by Ebner et al in detail [14].

\section{Chronic diseases}

Selected maternal pre-pregnancy diseases as defined by Kersten et al were stratified by body mass index [12].

Loading [MathJax]/jax/output/CommonHTML/jax.js 


\section{Educational level}

The stratification pattern for educational level followed the already published pattern [16]. Persons without a school diploma, being still at school or with five years, or less, of secondary school were pooled together and were referred to as having a low educational level. Persons with 6 years of secondary school

(German

Realsch|c|hluss' $)$ were $\in$ cluded $\in$ thesecond $\leq$ vel, referred $\rightarrow$ asthem $\leq$ educational $\leq$ vel. Thethird $\leq$ vel $\in$ cludedpersonswith8yearsofs Fachhochschulreife' or 'Abitur') and was referred to as the mid-high educational level. The highest educational level was assigned to persons who graduated and was referred to as a high educational level.

\section{Definitions of smoking and alcohol use}

In this paper, we did not analyse the dose effect of tobacco and alcohol consumption on pregnancy and neonatal outcomes. Therefore, we did not differentiate the cohort by the amount of alcohol consumed or tobacco smoked. Instead, we used a simple dichotomous classification:

smoke $\frac{r}{n}$ on - smoker' and drinker/non-drinker'. A woman was classified as a smoker if she declared to smoke during the last four weeks before delivery. Similarly, a woman was classified into the group of drinkers if she continued to drink alcohol during pregnancy, irrespective of the amount and time period of consumption.

\section{Definition of small-for-gestational-age and large-for-gestational age}

Small-for-gestational-age (SGA) was defined as birthweight below the $10^{\text {th }}$ percentile for their estimated gestational age. Large-for-gestational-age (LGA) was defined as a birth weight greater than the $90^{\text {th }}$ percentile adjusted for gestational age [17].

The gestational age was based upon the date of the mother's last menstrual period according to records in maternity card.

\section{Diagnosis of neonatal hypoglycaemia}

Neonatal hypoglycaemia was diagnosed using biochemical parameters according to national guidelines. A plasma glucose concentration of $45 \mathrm{mg} / \mathrm{ml}$ ( 2.5 $\mathrm{mmol} / \mathrm{l}$ ) within the first 24 hours after birth was used to diagnose neonatal hypoglycaemia. It was a routine policy to screen babies of mothers with gestational diabetes, preterm babies, babies with low birth weight $<2,500 \mathrm{~g}$, as well as all SGA- and LGA-babies for hypoglycaemia.

\section{Definition of neonatal asphyxia}

Neonatal (birth) asphyxia was defined according to medical diagnosis and included all ICD-10 codes P21.-, which included asphyxia of any grade (severe asphyxia, P21.0, mild and moderate birth asphyxia, P21.1, as well as unspecified birth asphyxia, P21.9). Medical diagnosis was taken from child's medical records.

\section{Conditions for admission to neonatal care}

According to the institutional policy and the national guideline, the personnel attach great importance to maintaining mother-child contact even in the case of pathology. Babies and their mothers were left at the maternity ward as long as the conditions allowed such a situation. The national guideline clearly defines when the neonate should be transferred to the neonatal ward, particularly when intravenous administration of glucose was necessary or in case of severe symptoms. For the purposes of the study, 'admission to neonatal care' included both neonatal intensive care and special care with respect to the newborn's condition and needs.

\section{Definition of monthly available equivalent income}

The need for housing space, electricity, and other essentials does not increase proportionally with the higher number of members in the household. To account for this phenomenon, we have used equivalence scales, based on the OECD-modified scale $[16,18]$.

\section{Potential mediators and confounders}

We have considered the following factors as potential mediators in the pathway between maternal low BMI before pregnancy and adverse pregnancy and neonatal outcomes: tobacco smoking and alcohol consumption during pregnancy, maternal age, available monthly equivalent income, and parity. These variables were assessed by the self-administered questionnaire. Ethnicity is another potential confounder; however, this factor could not be analysed because less than $2 \%$ of the population were not Caucasian.

\section{Statistical analyses}

All data were stored using a Microsoft Access 2002 (Microsoft Corporation, Redmond, WA, USA) database.

Continuous data are reported as the medians with the $25^{\text {th }}$ and $75^{\text {th }}$ percentiles; categorical data are expressed as the absolute numbers and/or percentages. Wilcoxon test and two-tailed $\chi 2$ test were used to calculate $p$-values for continuous and categorical variables, respectively. First, associations of socioeconomic status (educational level, income, employment status), and adverse habits (smoking and alcohol consumption) with mothers' low prepregnancy BMI were analysed by linear, logistic and multinomial logistic regressions adjusted for confounders. Second, associations of mothers' low preLoading [MathJax]/jax/output/CommonHTML/jax.js 
pregnancy BMI with adverse pregnancy and neonatal outcomes, such as birth weight, gestational age, hypoglycaemia, admission to the neonatal care unit, mode of delivery were analysed. The respective confounders used in the multivariate analyses are mentioned in the legends of each table. In all analyses, $p<$ 0.05 was considered statistically significant. All statistical analyses were carried out using Stata 16.0 (Stata Corporation, College Station, TX, USA).

\section{Results}

\section{Socioeconomic characteristics of the studied subpopulation}

Out of 5,801 mother-child-dyads participating in the baseline SNiP-I study, pre-pregnancy BMI was known for 4,667 mother-child-dyads, which were included into the current analysis (Table 1). Of these, 322 (6.9\%) women were underweight, and 3,085 (66.1\%) had normal weight. Bivariate analyses showed that underweight women were three years younger in median $(p<0.0001)$, and smoked more than twice as often as normal weight women during pregnancy $(p<0.0001)$. They had lower available equivalent income $(p<0.0001)$, and lower socioeconomic status (employment status and/or educational level, $p<0.001$ and $p<0.0001$, respectively) compared with women with normal weight.

\section{Chronic diseases as origin of the low pre-pregnancy BMI}

Selected chronic diseases were analysed for their association with the low pre-pregnancy BMI. The results of this analysis are shown in the Supplementary File1, since the prevalence figures were generally too low to include them into a profounder statistical analysis.

\section{Associations of socioeconomic factors with pre-pregnancy $\mathrm{BMI}<18.5$}

Increasing maternal age was associated with decreasing risk of being underweight ( $\mathrm{RR}=0.90 ; 95 \% \mathrm{Cl}, 0.88-0.92)$ (Table 2). Low educational level showed significant associations with maternal BMI $<18.5$ but not when confounders (see legend of Table 2 for details) were included (raw RR $=2.91 ; 95 \% \mathrm{Cl}, 1.86-4.54$, confounder-adjusted $\mathrm{RR}=1.21 ; 95 \% \mathrm{Cl}, 0.72-2.01)$. Underweight was associated with a 3.3-times higher risk $(\mathrm{RR}=3.34 ; \mathrm{Cl} 95 \%, 2.61-4.28)$ to smoke during pregnancy compared to women having normal weight. When confounders were included into the analysis, the risk decreased but it remained significant (RR = $2.54 ; \mathrm{Cl} 95 \%, 1.89-3.41)$.

Parity, alcohol consumption during pregnancy, middle or mid-high educational level were not associated with the BMI $<18.5$. We did not perform the analysis of the available equivalent income and employment status due to low number of available data for these two variables. Less than $50 \%$ of participants included into current analysis provided data on their available income or employment status.

\section{Association of maternal outcomes with BMl<18.5}

With reference to pregnancy outcome, we observed lower placenta weight $(520 \mathrm{~g}$ vs. $560 \mathrm{~g}, \mathrm{p}<0.0001)$ and more frequent premature labour $(32.8 \%$ vs. $20.6 \%$, $\mathrm{p}<0.0001$ ) in the group of underweight women compared to women with normal weight before pregnancy (Table 3 ). We did not observe significant differences regarding the prevalence of pregnancy-induced hypertension, GDM, preeclampsia and delivery mode between underweight and normal weight women.

Regression analysis has confirmed the association between the low pre-pregnancy BMI and lower placenta weight (adjusted $ß$-coefficient $=-36.3 \mathrm{~g}$; $95 \% \mathrm{Cl}$, $-58.4 \mathrm{~g}$ to $-13.5 \mathrm{~g})$ and premature labour $(\mathrm{OR}=1.74 ; 95 \% \mathrm{Cl}, 1.29-2.36)$ in the group of underweight women. Similar to bivariate analysis, we did not observe any association between BMl<18.5 and mode of birth, preeclampsia, GDM or pregnancy-induced hypertension (Table 3).

\section{Association of neonatal outcomes with BMK 18.5 in bivariate and regression analyses}

Bivariate analysis showed that newborns from underweight women were born lighter (boys 3,287g vs. 3,520g, $\mathrm{p}<0.001$; and girls $3,120 \mathrm{~g}$ vs. 3,331g, $\mathrm{p}<0.001$, for underweight and normal weight women, respectively), with low birth weight $(9.00 \%$ vs. $4.47 \%, \mathrm{p}<0.01)$, more often as SGA (14.3\% vs. $8.69 \%$, $\mathrm{p}<0.001)$ and less frequently as LGA babies $(4.97 \%$ vs. $10.4 \%, p<0.01)$ (Table 4$)$. They also suffered more frequently from asphyxia $(2.17 \%$ vs. $0.94 \%, p<0.05)$ but not from neonatal hypoglycaemia compared with babies of normal weight women.

Regression analyses revealed that a BMl 18.5 was a risk factor for babies to be born lighter, by $209 \mathrm{~g}$ for male infants (adjusted $\mathrm{B}$-coefficient, $95 \% \mathrm{Cl},-295 \mathrm{~g}$ to $-124 \mathrm{~g}$ ) and by $247 \mathrm{~g}$ for female infants (adjusted B-coefficient, $95 \% \mathrm{Cl},-336 \mathrm{~g}$ to $-157 \mathrm{~g}$ ). Low pre-pregnancy BMI doubled the risk of being born with low birth weight $(\mathrm{OR}=1.99 ; 95 \% \mathrm{Cl}, 1.24-3.21)$ and significantly increased risk of late preterm birth $(\mathrm{OR}=1.79 ; 95 \% \mathrm{Cl}, 1.17-2.73)$ but not of early preterm or post-term birth $(\mathrm{OR}=1.89 ; 95 \% \mathrm{Cl}, 0.70-5.09$, and $\mathrm{OR}=1.54 ; 95 \% \mathrm{Cl}, 0.58-4.05$, respectively). LGA was the only neonatal risk factor that was lower in the group of underweight women $(\mathrm{OR}=0.51 ; 95 \% \mathrm{Cl}, 0.29-0.90)$.

\section{Discussion}

Recent literature suggests that there is an association between low socioeconomic status $\left(\mathrm{BMI}<18.5 \mathrm{~kg} / \mathrm{m}^{2}\right)$ and low pre-pregnancy BMI , leading to adverse pregnancy and neonatal outcomes. We have investigated this hypothesis using data from the population-based rural-shaped birth cohort study 'Survey of Neonates in Pomerania' (SNiP-I) and analysed whether low socioeconomic status and adverse habits like smoking and alcohol consumption was associated with low pre-pregnancy BMI. Furthermore, the aim was to investigate how low pre-pregnancy BMI affected pregnancy and neonatal outcomes.

The prevalence of underweight in the SNiP I population was $6.9 \%$ and within the range reported for Europe and USA in a recent meta-analysis comprising more than 1.3 Mio pregnant women [3]. In Asia, particularly in Japan numbers were higher with 17 and 19\% [3, 19]. This can be partly explained by applying WHO percentiles for BMI rather than ethnic-specific percentiles [3]. Body image in young women is suspected to contribute to the high prevalence of pre-pregnancy

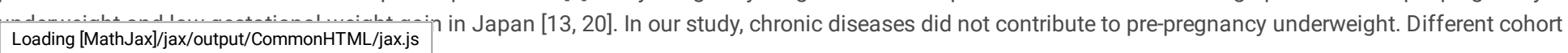


studies reported an association of low educational level with underweight in pregnant women [11, 21, 22]. However, in the SNiP-cohort low educational level was not associated with pre-pregnancy underweight after adjustment for parity and age. This may be partly explained the high proportion of female students in the young age group of women at child-bearing age in the university town of Greifswald.

The most prominent health behaviour associated with underweight in the SNiP-cohort was smoking. The prevalence of smoking within underweight women (40.5\%) was twice as high as in the whole SNiP-cohort and higher as the recently reported estimated prevalence of

smoking during pregnancy $(8.1 \%, 95 \% \mathrm{Cl} 4.0-12.2)$ for the European Region [23]. In a recent study from Italy (24), only $6.2 \%$ of underweight women still smoked during pregnancy [24]. Smoking is associated with lower education [11, 25].

Bakker et al reported smoking rates during pregnancy between $10.6 \%$ and $25.3 \%$ with the highest rate in the youngest women of the Generation $\mathrm{R}$ cohort [26].

In our cohort, a younger age was associated with pre-pregnancy underweight. This is in accordance with the literature [27, 28]. Age and body weight and constitute main determinants of body image in women. Particularly in Japan, weight control among young women is discussed to contribute to the high prevalence of pre-pregnancy underweight $[13,20]$. Therefore, age may be an indirectly potentially modifiable risk factor by counselling young women.

The risk for complications during pregnancy like pregnancy-induced hypertension, gestational diabetes mellitus and preeclampsia was not increased in underweight women in our cohort. Other reported even a lower risk for these complications in women with pre-pregnancy underweight [29-31].

Concerning neonatal outcome, women with pre-pregnancy underweight showed increased risk for low placental weight, late preterm births and low birth weight. This is in line with previous reports and meta-analyses [26, 30-34]. The association between pre-pregnancy underweight and low birth weight and preterm birth might be explained directly by a lack of nutrients resulting in diminished fetal growth or duration of gestation or indirectly through other associated factors such as smoking, poor diet or medical illness. Particularly maternal smoking was very frequent in underweight women in the SNiP-cohort. Recently, it was shown that beside known toxic effects smoking during pregnancy showed genome-wide methylation differences in cord blood [35].

The strengths of our analysis are the high population coverage of SNiP-I, the large number of participants, homogeneous ethnic compositions, geographically defined study region and a comprehensive dataset including medical and socioeconomic factors. While other cohort-based studies, such as LIFE in Leipzig or Generation R, investigate urban populations with highly inhomogeneous ethnic compositions, the SNiP I was conducted in a rural area on a population with high prevalence of obesity and low socioeconomic status compared to the populations in other regions of Germany [36-39].

A limitation of the study was that we calculated the pre-pregnancy BMI using mothers' self-reported data, which might be a source of error. However, a large systematic review showed that reporting error did not bias associations between pregnancy-related weight and birth outcomes [40].The missing analysis of data on the available monthly equivalent income may be seen as the second limitation of the study. However, data on income were available only for about half of participants and, if income is included in any regression analysis, obtained results will not be conclusive. We did not analyse gestational weight gain. Control of gestational weight gain within recommended ranges might improve neonatal outcome [3]. However, results from a recent multi-cohort analysis suggest that pre-pregnancy weight might be a more important target for interventions than gestational weight gain [28].

In conclusion, smoking during pregnancy and a younger age were identified as risk factors for maternal pre-pregnancy underweight which then was associated with preterm birth and low birth weight. Targeted measures like smoking cessation programs and counselling young women about the risk of staying too slim particularly for the offspring may improve outcome.

\section{Abbreviations}

BMI: Body mass index; Cl: Confidence interval; GDM: Gestational diabetes mellitus; GWG: Gestational weight gain; LGA: Large for gestational age; n: Number of cases included in a particular analysis; OR: Odds ratio; SGA: Small for gestational age; SNiP: Survey of Neonates in Pomerania

\section{Declarations}

\section{Ethics approval and consent to participate}

Research based on patient-related data and human DNA is strictly regulated by German law. The collection of detailed personal data, combined with the sampling of biomaterials, demands strict confidentiality. Our study complies with international guidelines of ethical research based on the Declaration of Helsinki. The study design was reviewed and approved by the Ethics Committee of the Board of Physicians Mecklenburg-Western Pomerania at the University of Greifswald (Reg.-Nr. III UV 20/00). Eligible women were asked for written informed consent; in cases of legally minor mothers, i.e., aged < 18 years, the additional signatures of the newborn's and legally minor mother's legal caregivers were required. The enrolment procedure was described in details by Ebner et al [14]. The written informed consent form included data assessment in face-to-face interviews, self-administered questionnaires and patient records. It also covered biosamples of blood. Furthermore, informed consent covered the storage of pseudonymized data as well as their analyses and publication.

The current study is a part of a population-based birth cohort 'Survey of Neonates in Pomerania' (SNiP) examining the health and socioeconomic information from 5801 mothers and their children. SNiP was designed as a multipurpose birth cohort to serve as a platform for studies of pregnancy complications, maternal and child health from pregnancy through to adulthood after completion of follow up. Therefore, all analyses from this database have to be regarded as secondary analyses.

\section{Consent for publication}

Loading [MathJax]/jax/output/CommonHTML/jax.js 
Not applicable.

\section{Availability of data and materials}

The paper is based on the data collected during the study 'Survey of Neonates in Pomerania', conducted at the University Medicine Greifswald, Greifswald, Germany, between 2002 and 2008. Data from the SNIP are available via https://www.fvcm.med.uni-greifswald.de/dd_service/ data_use_intro.php?lang=ger. The repository is managed by the Research Cooperation Community Medicine (RCC) of the University of Greifswald, Germany. This data repository allows any researcher to register and apply for access. It provides a data dictionary and online application tools for accessing the data. Upon application by the registered users, the RCC determines whether to grant access to the data, based on scientific guidelines.

\section{Competing interests}

The authors declare that they have no competing interests.

\section{Funding}

The SNiP was financially supported by grants from the Federal Ministry of Education and Research (grant no. ZZ 96030, and NBL3 Program, grant no. 01 ZZ 0103), the Excellence Support Programme of the Federal State of Mecklenburg-Western Pomerania (grant no. UG 07 034), and the Epidemiological Study on Childhood Cancer and Malformations in the Vicinity of Nuclear Power Plants (Stsch 4493). The medical faculty of the Ernst Moritz Arndt University of Greifswald provided additional support in the form of a training grant to Dr. Anja Erika Lange.

The current analysis presented in this paper was performed without further external support. The funders had no role in study design, data collection and analysis, decision to publish, or preparation of the manuscript.

\section{Authors' contribution}

GD and MH were responsible for writing the manuscript, and AEL contributed to acquisition of data and writing the manuscript. GD, AEL, HA and JF analysed and interpreted the data. TI and HA conducted statistical analyses and contributed to their interpretation. MZ has made substantial contribution to conception and design of the obstetrical issues of the study, as well as to acquisition of data. MH, AEL and GD originally conceived of the study. MH is the principle investigator of SNiP and has made substantial contribution to analysis and interpretation of data and writing the manuscript. All authors were involved in revising the manuscript critically for important intellectual content. All authors have read the final version, given final approval of the version to be published, and agreed to

be accountable for all aspects of the work.

\section{Acknowledgements}

Not applicable

\section{Authors' information}

GD and AEL contributed equally to this work. This work is part of the thesis of JF.

\section{References}

1. Aune D, Saugstad OD, Henriksen T, Tonstad S: Maternal body mass index and the risk of fetal death, stillbirth, and infant death: a systematic review and meta-analysis. JAMA 2014, 311(15):1536-1546.

2. Yu Z, Han S, Zhu J, Sun X, Ji C, Guo X: Pre-pregnancy body mass index in relation to infant birth weight and offspring overweight/obesity: a systematic review and meta-analysis. PLoS One 2013, 8(4):e61627.

3. Goldstein RF, Abell SK, Ranasinha S, Misso ML, Boyle JA, Harrison CL, Black MH, Li N, Hu G, Corrado F et al: Gestational weight gain across continents and ethnicity: systematic review and meta-analysis of maternal and infant outcomes in more than one million women. BMC Med 2018, 16(1):153.

4. Abenhaim HA, Kinch RA, Morin L, Benjamin A, Usher R: Effect of prepregnancy body mass index categories on obstetrical and neonatal outcomes. Arch Gynecol Obstet 2007, 275(1):39-43.

5. Hinkle SN, Albert PS, Mendola P, Sjaarda LA, Boghossian NS, Yeung E, Laughon SK: Differences in risk factors for incident and recurrent small-forgestational-age birthweight: a hospital-based cohort study. BJOG 2014, 121(9):1080-1088; discussion 1089.

6. Leng J, Hay J, Liu G, Zhang J, Wang J, Liu H, Yang X, Liu J: Small-for-gestational age and its association with maternal blood glucose, body mass index and stature: a perinatal cohort study among Chinese women. BMJ open 2016, 6(9):e010984.

7. Bastek JA, Sammel MD, Pare E, Srinivas SK, Posencheg MA, Elovitz MA: Adverse neonatal outcomes: examining the risks between preterm, late preterm, and term infants. Am J Obstet Gynecol 2008, 199(4):367 e361-368.

8. Crump C, Sundquist K, Sundquist J, Winkleby MA: Gestational age at birth and mortality in young adulthood. JAMA 2011, 306(11):1233-1240.

9. Langley-Evans SC: Fetal programming of cardiovascular function through exposure to maternal undernutrition. Proc Nutr Soc 2001, 60(4):505-513.

10. Reeves S, Bernstein I: Effects of maternal tobacco-smoke exposure on fetal growth and neonatal size. Expert Rev Obstet Gynecol 2008, 3(6):719-730.

Loading [MathJax]/jax/output/CommonHTML/jax.js 
11. Baron R, Mannien J, te Velde SJ, Klomp T, Hutton EK, Brug J: Socio-demographic inequalities across a range of health status indicators and health behaviours among pregnant women in prenatal primary care: a cross-sectional study. BMC Pregnancy Childbirth 2015, 15:261.

12. Kersten I, Lange AE, Haas JP, Fusch C, Lode H, Hoffmann W, Thyrian JR: Chronic diseases in pregnant women: prevalence and birth outcomes based on the SNiP-study. BMC Pregnancy Childbirth 2014, 14:75.

13. Normile D: Staying slim during pregnancy carries a price. Science 2018, 361(6401):440.

14. Ebner A, Thyrian JR, Lange A, Lingnau ML, Scheler-Hofmann M, Rosskopf D, Zygmunt M, Haas JP, Hoffmann W, Fusch C: Survey of Neonates in Pomerania (SNiP): a population-based birth study-objectives, design and population coverage. Paediatr Perinat Epidemio/2010, 24(2):190-199.

15. Organization WH: Obesity: Preventing and managing the global epidemic. Geneva: World Helath Organization (WHO Technical Report Series) $2000,394$.

16. Domanski G, Lange AE, Ittermann T, Allenberg H, Spoo RA, Zygmunt M, Heckmann M: Evaluation of neonatal and maternal morbidity in mothers with gestational diabetes: a population-based study. BMC Pregnancy Childbirth 2018, 18(1):367.

17. Voigt M, Rochow N, Schneider KT, Hagenah HP, Scholz R, Hesse V, Wittwer-Backofen U, Straube S, Olbertz D: [New percentile values for the anthropometric dimensions of singleton neonates: analysis of perinatal survey data of 2007-2011 from all 16 states of Germany]. Z Geburtshilfe Neonatol 2014, 218(5):210-217.

18. Hagenaars A, Vos KD, Zaidi MA: Poverty statistics in the late 1980s: Research based on micro-data. Luxembourg: Off of Official Publ of the Europ Communities; 19941994.

19. Morisaki N, Nagata C, Jwa SC, Sago H, Saito S, Oken E, Fujiwara T: Pre-pregnancy BMI-specific optimal gestational weight gain for women in Japan. J Epidemiol 2017, 27(10):492-498.

20. Ogawa K, Morisaki N, Sago H, Fujiwara T, Horikawa R: Association between women's perceived ideal gestational weight gain during pregnancy and pregnancy outcomes. Sci Rep 2018, 8(1):11574.

21. Boudet-Berquier J, Salanave B, Desenclos JC, Castetbon K: Sociodemographic factors and pregnancy outcomes associated with prepregnancy obesity: effect modification of parity in the nationwide Epifane birth-cohort. BMC Pregnancy Childbirth 2017, 17(1):273.

22. Holowko N, Chaparro MP, Nilsson K, Ivarsson A, Mishra G, Koupil I, Goodman A: Social inequality in pre-pregnancy BMI and gestational weight gain in the first and second pregnancy among women in Sweden. J Epidemiol Community Health 2015, 69(12):1154-1161.

23. Lange S, Probst C, Rehm J, Popova S: National, regional, and global prevalence of smoking during pregnancy in the general population: a systematic review and meta-analysis. Lancet Glob Health 2018, 6(7):e769-e776.

24. Zanardo V, Mazza A, Parotto M, Scambia G, Straface G: Gestational weight gain and fetal growth in underweight women. Ital J Pediatr 2016, $42(1): 74$.

25. Hoebel J, Kuntz B, Kroll LE, Finger JD, Zeiher J, Lange C, Lampert T: Trends in Absolute and Relative Educational Inequalities in Adult Smoking Since the Early 2000s: The Case of Germany. Nicotine Tob Res 2018, 20(3):295-302.

26. Bakker R, Steegers EA, Biharie AA, Mackenbach JP, Hofman A, Jaddoe VW: Explaining differences in birth outcomes in relation to maternal age: the Generation R Study. BJOG 2011, 118(4):500-509.

27. Heslehurst N, Ells LJ, Simpson H, Batterham A, Wilkinson J, Summerbell CD: Trends in maternal obesity incidence rates, demographic predictors, and health inequalities in 36,821 women over a 15-year period. BJOG 2007, 114(2):187-194.

28. LifeCycle Project-Maternal O, Childhood Outcomes Study G, Voerman E, Santos S, Inskip H, Amiano P, Barros H, Charles MA, Chatzi L, Chrousos GP et al: Association of Gestational Weight Gain With Adverse Maternal and Infant Outcomes. JAMA 2019, 321(17):1702-1715.

29. Bhattacharya S, Campbell DM, Liston WA, Bhattacharya S: Effect of Body Mass Index on pregnancy outcomes in nulliparous women delivering singleton babies. BMC Public Health 2007, 7:168.

30. Santos S, Voerman E, Amiano P, Barros H, Beilin LJ, Bergstrom A, Charles MA, Chatzi L, Chevrier C, Chrousos GP et al: Impact of maternal body mass index and gestational weight gain on pregnancy complications: an individual participant data meta-analysis of European, North American and Australian cohorts. BJOG 2019, 126(8):984-995.

31. Sebire NJ, Jolly M, Harris J, Regan L, Robinson S: Is maternal underweight really a risk factor for adverse pregnancy outcome? A population-based study in London. BJOG 2001, 108(1):61-66.

32. Dzakpasu S, Fahey J, Kirby RS, Tough SC, Chalmers B, Heaman MI, Bartholomew S, Biringer A, Darling EK, Lee LS et al: Contribution of prepregnancy body mass index and gestational weight gain to adverse neonatal outcomes: population attributable fractions for Canada. BMC Pregnancy Childbirth 2015, 15:21.

33. Han Z, Mulla S, Beyene J, Liao G, McDonald SD, Knowledge Synthesis G: Maternal underweight and the risk of preterm birth and low birth weight: a systematic review and meta-analyses. Int J Epidemiol 2011, 40(1):65-101.

34. Liu P, Xu L, Wang Y, Zhang Y, Du Y, Sun Y, Wang Z: Association between perinatal outcomes and maternal pre-pregnancy body mass index. Obesity reviews : an official journal of the International Association for the Study of Obesity 2016, 17(11):1091-1102.

35. Kupers LK, Xu X, Jankipersadsing SA, Vaez A, la Bastide-van Gemert S, Scholtens S, Nolte IM, Richmond RC, Relton CL, Felix JF et al: DNA methylation mediates the effect of maternal smoking during pregnancy on birthweight of the offspring. Int J Epidemiol 2015, 44(4):1224-1237.

36. Jaddoe VW, van Duijn CM, van der Heijden AJ, Mackenbach JP, Moll HA, Steegers EA, Tiemeier H, Uitterlinden AG, Verhulst FC, Hofman A: The Generation R Study: design and cohort update until the age of 4 years. European journal of epidemiology 2008, 23(12):801-811.

37. John U, Greiner B, Hensel E, Ludemann J, Piek M, Sauer S, Adam C, Born G, Alte D, Greiser E et al: Study of Health In Pomerania (SHIP): a health examination survey in an east German region: objectives and design. Soz Praventivmed 2001, 46(3):186-194.

38. Kurth BM, Kamtsiuris P, Holling H, Schlaud M, Dolle R, Ellert U, Kahl H, Knopf H, Lange M, Mensink GB et al: The challenge of comprehensively mapping Loading [MathJax]/jax/output/CommonHTML/jax.js survey: design of the German KiGGS-Study. BMC Public Health 2008, 8:196.

Page $7 / 11$ 
39. Poulain T, Baber R, Vogel M, Pietzner D, Kirsten T, Jurkutat A, Hiemisch A, Hilbert A, Kratzsch J, Thiery J et al: The LIFE Child study: a population-based perinatal and pediatric cohort in Germany. European journal of epidemiology 2017, 32(2):145-158.

40. Headen I, Cohen AK, Mujahid M, Abrams B: The accuracy of self-reported pregnancy-related weight: a systematic review. Obesity reviews : an official journal of the International Association for the Study of Obesity 2017, 18(3):350-369.

\section{Tables}

Table 1. Maternal socioeconomic characteristics and selected health behavior of women with pre-pregnancy underweight and normal weight from the baseline SNiP-I cohort. Only singleton pregnancies were analysed $(n=4,667)$.

\begin{tabular}{|c|c|c|c|c|}
\hline & Underweight & Normal weight & Total & $p^{*}$ \\
\hline & $\mathrm{BMI}<18.5$ & BMI $18.5-24.99$ & $n=4,667$ & \\
\hline & $\mathrm{n}=322$ & $\mathrm{n}=3,085$ & & \\
\hline Percent of the population, $\%$ & 6.9 & 66.1 & 100 & - \\
\hline Pre-pregnancy BMI, median (25th $/ 75^{\text {th }}$ percentiles) & $17.9(17.3 / 18.3)$ & $21.5(20.2 / 23.0)$ & $22.4(20.3 / 25.4)$ & $<0.0001$ \\
\hline Maternal age, years, median $\left(25^{\text {th }} / 75^{\text {th }}\right.$ percentiles; $\left.n\right)$ & 24 & 27 & 27 & $<0.0001$ \\
\hline & $(21 / 28 ; n=322)$ & $(24 / 31 ; n=3,081)$ & $(24 / 31 ; n=4,662)$ & \\
\hline Available equivalent income, $€$, median $\left(25^{\text {th }} / 75^{\text {th }}\right.$ percentiles; $\left.n\right)$ & 796 & 1,083 & 1,061 & $<0.0001$ \\
\hline & $\begin{array}{l}(442 / 1,326 \\
\mathrm{n}=160)\end{array}$ & $\begin{array}{l}(650 / 1,588 \\
n=1,550)\end{array}$ & $\begin{array}{l}(619 / 1,503 \\
\mathrm{n}=2,419)\end{array}$ & \\
\hline Smoking during pregnancy, $\mathrm{n}(\%)$ & & & & \\
\hline Yes & $125(40.5)$ & $500(16.9)$ & $866(19.4)$ & $<0.0001$ \\
\hline No & $184(59.5)$ & $2,460(83.1)$ & $3,597(80.6)$ & \\
\hline $\begin{array}{l}\text { Alcohol consumption } \\
\text { during pregnancy, n, (\%) }\end{array}$ & & & & \\
\hline Yes & $64(20.5)$ & 735 (24.3) & $1,034(22.6)$ & 0.131 \\
\hline No & $248(79.5)$ & $2,284(75.7)$ & $3,534(77.4)$ & \\
\hline Parity: & & & & 0.234 \\
\hline First birth, n (\%) & $172(53.4)$ & $1,493(48.4)$ & $2,153(46.2)$ & \\
\hline Second birth, n (\%) & $90(28.0)$ & $952(30.9)$ & $1,430(30.7)$ & \\
\hline Third and more birth, $\mathrm{n}(\%)$ & $60(18.6)$ & $638(20.7)$ & $1,079(23.1)$ & \\
\hline Educational level: & & & & $<0.0001$ \\
\hline Low, n (\%) & $76(24.4)$ & $370(12.4)$ & $685(15.2)$ & \\
\hline Middle, n (\%) & $152(48.9)$ & $1,530(51.3)$ & $2,383(52.7)$ & \\
\hline Mid-high, n (\%) & $53(17.0)$ & $659(22.1)$ & $902(20.0)$ & \\
\hline High, n (\%) & $30(9.65)$ & $425(14.2)$ & $548(12.1)$ & \\
\hline Employment status: & & & & 0.001 \\
\hline Full-time, n (\%) & $73(32.3)$ & $959(46.3)$ & $1,361(42.6)$ & \\
\hline Part-time, n (\%) & $38(16.8)$ & $354(17.1)$ & $548(17.1)$ & \\
\hline On leave, n (\%) & $20(8.9)$ & $127(6.1)$ & $209(6.5)$ & \\
\hline Still in educational or professional training, $\mathrm{n}(\%)$ & $17(7.5)$ & $119(5.7)$ & $183(5.7)$ & \\
\hline Unemployed, n (\%) & $78(34.5)$ & $514(24.8)$ & $894(28.0)$ & \\
\hline
\end{tabular}

${ }^{*} \mathrm{p}$-value for differences between groups, BMI <18.5 vs. BMI $18.5-24.99$, (Wilcoxon-Test for continuous variables and two-tailed $\chi 2$-test for categorial variables)

Table 2. Associations between maternal BMI and selected socioeconomic factors for the group of underweight women. The group of women group with normal BMI (BMI 18.5 - 24.99) was used as a reference group; RR - relative risk ratio. 


\begin{tabular}{lll} 
Socioeconomic factor & RR $(95 \%$ Cl) & \\
\cline { 2 - 3 } & raw & adjusted \\
\hline Maternal age & $0.90(0.88-0.92)$ & -a \\
\hline Educational level & & \\
\hline Low & $2.91(1.86-4.54)$ & $1.21(0.72-2.01)^{\mathbf{b}}$ \\
\hline middle & $1.41(0.94-2.11)$ & $0.88(0.57-1.36)^{\mathbf{b}}$ \\
\hline mid-high & $1.14(0.72-1.81)$ & $0.85(0.57-1.36)^{\mathbf{b}}$ \\
\hline High & 1.00 & 1.00 \\
\hline Smoking during pregnancy & $3.34(2.61-4.28)$ & $2.54(1.89-3.41)^{\mathbf{c}}$ \\
\hline Alcohol during pregnancy & $0.80(0.60-1.07)$ & $0.90(0.67-1.21)^{\mathbf{d}}$ \\
\hline Parity & & \\
\hline First pregnancy & 1.00 & 1.00 \\
\hline Two pregnancies & $0.82(0.63-1.07)$ & $1.12(0.84-1.49)^{\mathbf{e}}$ \\
\hline Three or more pregnancies & $0.82(0.60-1.11)$ & $1.43(1.00-2.04)^{\mathbf{e}}$
\end{tabular}

a - only raw value is shown as maternal age cannot be affected by any other factor; $b$ - the highest educational level was a reference group, adjusted for maternal age and parity; c - adjusted for maternal age, parity, educational level, and alcohol use during the pregnancy; $d$ - adjusted for smoking during pregnancy, maternal age, parity, and educational level; e - women with first pregnancy were reference group, adjusted for educational level and maternal age

Table 3. Comparisons of pregnancy outcomes for women with pre-pregnancy underweight and normal weight in singleton pregnancies of the SNiP-I cohort.

\begin{tabular}{|c|c|c|c|c|}
\hline \multirow{2}{*}{ Parameter } & Underweight & Normal weight ${ }^{\S}$ & \multicolumn{2}{|c|}{ B-coef./OR/RR (95\% Cl) } \\
\hline & $\mathrm{n}=\mathbf{3 2 2}$ & $n=3,085$ & & \\
\hline raw & adjusted & & & \\
\hline Placenta weight, g, median $\left(25^{\text {th }} / 75^{\text {th }} \text { percentile; } n\right)^{\star k \star k}$ & $\begin{array}{l}520 \\
(450 / 600 \\
n=147)\end{array}$ & $\begin{array}{l}560 \\
(480 / 640 \\
\mathrm{n}=1,412)\end{array}$ & $\begin{array}{l}-34.9(-56.3 \text { to } \\
-13.5)^{a}\end{array}$ & $\begin{array}{l}-36.3(-58.4 \text { to } \\
-13.5)^{\mathrm{a}}\end{array}$ \\
\hline Pregnancy-induced hypertension. $n(\%)^{\text {n.s. }}$ & $1(0.31)$ & $45(1.46)$ & $0.21(0.03-1.53)^{b}$ & $0.27(0.04-1.98)^{b}$ \\
\hline GDM, n (\%) $)^{\text {n.s. }}$ & $8(2.48)$ & $99(3.21)$ & $0.77(0.37-1.59)^{b}$ & $1.00(0.48-2.10)^{b}$ \\
\hline Premature labour, $\mathrm{n}(\%)^{\star \star * *}$ & $84(32.8)$ & $464(20.6)$ & $1.88(1.42-2.49)^{b}$ & $1.74(1.29-2.36)^{b}$ \\
\hline Preeclampsia, n (\%) $)^{\text {n.s. }}$ & $6(1.86)$ & $40(1.30)$ & $1.45(0.61-3.44)^{b}$ & $1.70(0.70-4.12)^{b}$ \\
\hline \multicolumn{5}{|l|}{ Mode of birth, $n(\%)^{\text {n.s. }}$} \\
\hline Spontaneous (base outcome) & $238(73.9)$ & $2,268(73.7)$ & - & - \\
\hline Primary C-section & $36(11.2)$ & $357(11.6)$ & $0.96(0.67-1.39)^{c}$ & $1.17(0.80-1.71)^{\mathrm{c}}$ \\
\hline Secondary C-section & $35(10.9)$ & $327(10.6)$ & $1.02(0.70-1.48)^{\mathrm{c}}$ & $1.00(0.67-1.49)^{\mathrm{c}}$ \\
\hline Operative & $13(4.04)$ & $125(4.06)$ & $0.99(0.55-1.78)^{\mathrm{c}}$ & $0.92(0.48-1.75)^{\mathrm{C}}$ \\
\hline
\end{tabular}

$\S$ - reference group; OR - Odds ratio; $ß$-coef. - $ß$-coefficient; $\mathrm{RR}$ - risk ratio; $\mathrm{Cl}$ - confidence interval; GDM - gestational diabetes mellitus a - $ß$-coefficient; $\mathrm{b}$ - Odds ratio; $c$ - risk ratio; significance level of differences between groups for individual parameter: ${ }^{*}-p \leq 0.05,{ }^{* *}-p \leq 0.01,{ }^{\star * \star}-p \leq 0.001,{ }^{* \star \star *}-p \leq$ 0.0001 , n.s. - not significant $(p>0.05)$ 
Table 4. Comparisons of selected neonatal outcomes for women with pre-pregnancy underweight and normal weight in singleton pregnancies of the SNiP-I cohort.

\begin{tabular}{|c|c|c|c|c|}
\hline \multirow[t]{2}{*}{ Parameter } & Underweight & & \multicolumn{2}{|c|}{ B-coef./OR/RR $(95 \% \mathrm{Cl})^{\mathrm{g}}$} \\
\hline & $\mathrm{n}=322$ & $\mathrm{n}=3,085$ & & \\
\hline raw & adjusted & & & \\
\hline \multicolumn{5}{|c|}{ Birth weight, g, median $\left(25^{\text {th }} / 75^{\text {th }}\right.$ percentile; $\left.n\right)$} \\
\hline Male $(n=2,468)^{* \star * *}$ & $\begin{array}{l}3,287(2,935 / 3,662 \\
\mathrm{n}=180)\end{array}$ & $\begin{array}{l}3,520(3,180 / 3,820 \\
n=1,637)\end{array}$ & $\begin{array}{l}-209(-295 \text { to } \\
-124)\end{array}$ & $\begin{array}{l}-122(-195 \text { to } \\
-48)\end{array}$ \\
\hline Female $(n=2,199)^{\star \star \star}$ & $\begin{array}{l}3,120(2,900 / 3,340 \\
n=142)\end{array}$ & $\begin{array}{l}3,331(3,050 / 3,650 \\
n=1,448)\end{array}$ & $\begin{array}{l}-247(-336 \text { to } \\
-157)\end{array}$ & $\begin{array}{l}-142(-225 \text { to } \\
-59)\end{array}$ \\
\hline \multicolumn{5}{|l|}{ Gestational age at birth, $\mathrm{n}(\%)^{* *}$} \\
\hline < 32th week (early preterm) & $5(1.55)$ & $26(0.84)$ & $1.96(0.75-5.16)$ & $1.89(0.70-5.09)$ \\
\hline 32th-36th week (late preterm) & $33(10.3)$ & $174(5.64)$ & $1.94(1.31-2.87)$ & $1.79(1.17-2.73)$ \\
\hline 37th-41th week (term) & $279(86.7)$ & $2,850(92.4)$ & 1.00 & 1.00 \\
\hline > 41th week (post-term) & $5(1.55)$ & $35(1.13)$ & $1.46(0.57-3.75)$ & $1.54(0.58-4.05)$ \\
\hline $\mathrm{LBW}^{\mathrm{c}}, \mathrm{n}(\%)^{\star *}$ & $29(9.00)$ & $138(4.47)$ & $2.24(1.44-3.48)$ & $1.99(1.24-3.21)$ \\
\hline $\mathrm{SGA}^{\mathrm{d}}, \mathrm{n}(\%)^{\star * *}$ & $46(14.3)$ & $268(8.69)$ & $1.75(1.25-2.45)$ & $1.42(0.99-2.04)$ \\
\hline LGA $^{\mathrm{e}}, \mathrm{n}(\%)^{\star \star}$ & $16(4.97)$ & $320(10.4)$ & $0.45(0.27-0.76)$ & $0.51(0.29-0.90)$ \\
\hline Neonatal hypoglycaemia, n (\%) & $14(4.35)$ & $89(2.88)$ & $1.53(0.86-2.72)$ & $1.65(0.91-2.97)$ \\
\hline Neonatal asphyxia ${ }^{f}, \mathrm{n}(\%)^{*}$ & $7(2.17)$ & $29(0.94)$ & $2.34(1.02-5.39)$ & $2.01(0.81-4.99)$ \\
\hline
\end{tabular}

$\S$ - reference group; OR - odds ratio; ß-coef. - ß-coefficient; RR - risk ratio; Cl - confidence interval; a - gestational weight gain; b - gestational diabetes mellitus; $c$ - low birth weight $(<2,500 \mathrm{~g})$; $\mathrm{d}$ - small-for gestational-age (birth weight $<10^{\text {th }}$ percentile); e - large-for-gestational-age (birth weight $>90^{\text {th }}$ percentile); $f$ - ICD-10 codes P21.; g - OR adjusted for confounders: maternal age, educational level, parity, smoking and alcohol use in pregnancy; significance level of differences between groups for individual parameter: $*-p \leq 0.05, \star \star-p \leq 0.01$, $* \star \star-p \leq 0.001$, $* \star \star \star-p \leq 0.0001$, n.s. - not significant $(p>$ 0.05)

\section{Figures}

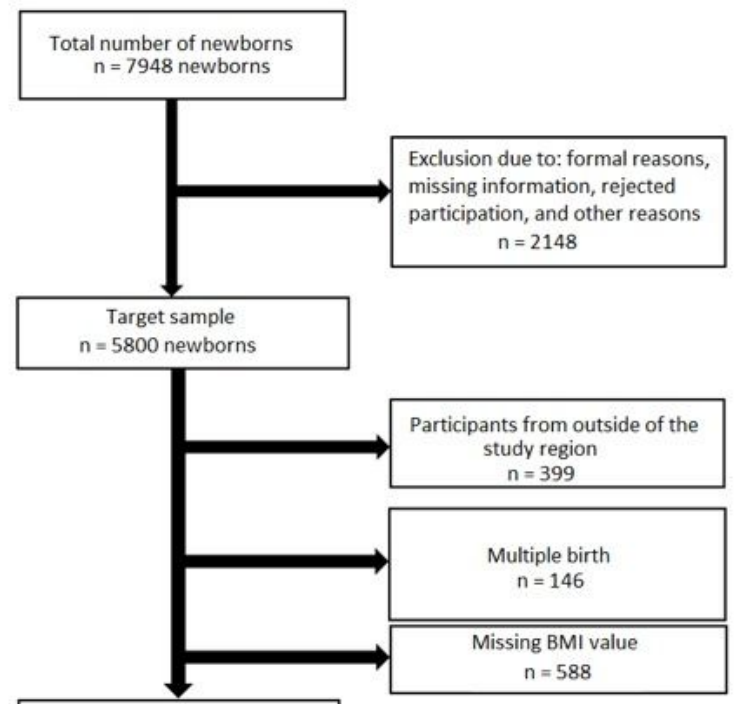

Subgroup of the total SNiP-I Study population included into this analysis $n=4667$ 
Flow diagramm showing selection procedure apply to data from SNiP I Study

Loading [MathJax]/jax/output/CommonHTML/jax.js

Page $11 / 11$ 